\title{
Calcified nanostructured silicon wafer surfaces for biosensing: Effects of surface modification on bioactivity
}

\author{
Robert P. Weis ${ }^{\mathrm{a}}$, Jean-Luc Montchamp ${ }^{\mathrm{a}}$, Jeffery L. Coffer ${ }^{\mathrm{a}}$, Darlene Gamal Attiah ${ }^{\mathrm{b}}$ and \\ Tejal A. Desai ${ }^{\mathrm{b}, *}$ \\ ${ }^{a}$ Department of Chemistry, Texas Christian University, Ft. Worth, TX 761290, USA \\ ${ }^{\mathrm{b}}$ Department of Bioengineering Boston University, Boston, MA 02215, USA
}

\begin{abstract}
The growth of known biologically-relevant mineral phases on semiconducting surfaces is one strategy to explicitly induce bioactivity in such materials, either for sensing or drug delivery applications. In this work, we describe the use of a spark ablation process to fabricate deliberate patterns of $\mathrm{Ca}_{10}\left(\mathrm{PO}_{4}\right)_{6}(\mathrm{OH})_{2}$ on crystalline $\mathrm{Si}$ (calcified nanoporous silicon). These patterns have been principally characterized by scanning electron microscopy in conjunction with elemental characterization by energy dispersive $\mathrm{x}$-ray analysis. This is followed by a detailed comparison of the effects of fibroblast adhesion and proliferation onto calcified nanoporous Si, calcified nanoporous Si derivatized with alendronate, as well as control samples of an identical surface area containing porous $\mathrm{SiO}_{2}$. Fibroblast adhesion and proliferation assays demonstrate that a higher density of cells grow on the $\mathrm{Ca}_{3}\left(\mathrm{PO}_{4}\right)_{2}$ /porous $\mathrm{Si} / \mathrm{SiO}_{2}$ structures relative to the alendronate-modified surfaces and porous $\mathrm{Si}_{/} / \mathrm{SiO}_{2}$ samples.
\end{abstract}

Keywords: Calcium phosphate, silicon, fibroblasts, biosensor

\section{Introduction}

Silicon's central role in electronic devices is continually enhanced by ongoing shrinkage of individual features, currently in the nanometer size regime. While a dearth of examples demonstrating the application of crystalline Si to biomaterial applications exist $[1,4]$, the appeal of exploiting the rich technological knowledge base of $\mathrm{Si}$ in this context drives continuing investigations in a number of laboratories. One specific area of interest involves the formation of crystalline and/or amorphous films of calcium phosphate (the inorganic constituent of bone) on semiconducting porous Si substrates [5-8]. In addition to blanket films, it has been recently demonstrated that it is possible to form delib-

*Adrress for correspondence: Tejal A. Desai, Ph.D., Associate Professor, Department of Biomedical Engineering, Boston University, 44 Cummington Street, Boston, MA 02215, USA. Tel.: +1 617 358 3054; Fax: +1 617353 6766; E-mail: tdesai@bu.edu. erate patterns of this material on porous $\mathrm{Si}$ surfaces [9, 10]. Such structures also have the potential to act as electronically-responsive therapy vehicles when doped with useful platinum antitumor drugs such as cis-platin and carbo-platin [11]. Another potential area of study falls within the biosensor category, where incorporation of molecules into the calcium phosphate matrix eliciting an electrical or optical response upon binding to biomolecules could also be useful [12].

In any of the above applications, the surface chemistry of the calcified silicon surface clearly plays a crucial role in mediating recognition events essential to bio-activity or compatibility. For a given surface composition, it is also important to derivatize this interface in order to refine chemical selectivity in molecular binding at the calcified surface. The class of bis-phosphonate derivatives of the general formula $\left(\mathrm{H}_{2} \mathrm{O}_{3} \mathrm{P}\right)_{2} \mathrm{C}(\mathrm{OH}) \mathrm{R}$ are appealing in this regard given the diverse opportunities for subsequent chemical alteration of the ligand it- 
self as well as their extensive use in bone-related disease therapies [13]. We have recently demonstrated proof-of-concept of this synthetic methodology by covalent attachment of a bis-phosphonate amine linker $\left(\mathrm{H}_{2} \mathrm{O}_{3} \mathrm{P}\right)_{2} \mathrm{C}(\mathrm{OH})\left(\mathrm{CH}_{2}\right)_{3} \mathrm{NH}_{2}$ (alendronate) to the calcium phosphate surface, along with coupling a fluorescein chromophore (in the form of an isothiocyanate derivative) to the exposed amine moiety [14].

For these approaches a key issue that remains unresolved is the effect of surface modification on the adhesion and viability of relevant cells on a given calcified nanoporous Si surface. This is critical to ensuring that such platforms can be safely used in in vivo settings. In this work, we describe the use of our spark ablation process to fabricate deliberate patterns of $\mathrm{Ca}_{10}\left(\mathrm{PO}_{4}\right)_{6}(\mathrm{OH})_{2}$ on crystalline $\mathrm{Si}$. These patterns have been principally characterized by scanning electron microscopy (SEM) in conjunction with elemental characterization by energy dispersive $\mathrm{x}$-ray analysis (EDX). This is followed by a detailed comparison of the effects of fibroblast adhesion and proliferation onto calcified nanoporous $\mathrm{Si}$, calcified nanoporous $\mathrm{Si}$ derivatized with alendronate, as well as control samples of an identical surface area containing porous $\mathrm{SiO}_{2}$.

\section{Experimental section}

Sample fabrication. For the spark processing method, square pieces $(15 \mathrm{~mm} \times 15 \mathrm{~mm})$ of p-type, $<100\rangle$, boron-doped CZ Si (6-8 $\Omega$-cm) were employed. In order to produce more effective incorporation of calcium phosphate onto the porous surface, a modification of our previously reported procedure was used [10]. First, a finite amount of polycaprolactone is added to an acetone slurry of $\mathrm{Ca}_{10}\left(\mathrm{PO}_{4}\right)_{6}(\mathrm{OH})_{2}$ (Aldrich) in order to assist in adhesion of the calcium phosphate during the ablation event. This mixture is deposited on the wafer surface and allowed to dry, producing a layer of calcium phosphate/PCL covering the entire $\mathrm{Si}$ source. The sample was then connected to the cathode of an Electro Technics Products Tesla coil providing a high frequency $(15 \mathrm{KHz})$, high voltage $\left(\sim 10^{4} \mathrm{~V}\right)$, low current (several $\mathrm{mA}$ ) spark with a typical electrode gap of $0.2 \mathrm{~mm}$. For pattern formation, the cathode tip is translated to the desired location(s) with a custom-built stage that is manipulated by microprocessor-controlled motors (New Focus); for these particular experiments, square arrays of $1.8 \mathrm{~mm} \times 1.8 \mathrm{~mm}$ were fabricated. For optimal preparation, samples were ablated three successive times (for 45 minutes each) utilizing the application of mixtures containing different ratios of PCL to calcium phosphate (by mass). The first ablation entailed a $20 \%$ PCL : calcium phosphate mixture, the second, a $10 \%$ solution, followed by a third and final ablation using a 5\% mixture of PCL to calcium phosphate. After each processing step, samples were washed with de-ionized $\mathrm{H}_{2} \mathrm{O}$ and acetone, then dried under a stream of dry nitrogen. For surface modification with alendronate, a given calcium phosphate / porous silicon film is immersed in a $5 \mathrm{mM}$ aqueous solution of $\left(\mathrm{H}_{2} \mathrm{O}_{3} \mathrm{P}\right)_{2} \mathrm{C}(\mathrm{OH})\left(\mathrm{CH}_{2}\right)_{3} \mathrm{NH}_{2}$. After immersion for $\sim 12 \mathrm{hr}$ at room temperature, the wafer sample is removed, washed thoroughly with water, and dried in a stream of dry nitrogen. For controls, porous $\mathrm{SiO}_{2}$ wafer samples were prepared by utilizing the identical procedures as described above except for the absence of any calcium phosphate or alendronate during the sparking event(s).

Instrumentation. Samples were analyzed by a Hitachi S-3000N VP-SEM with an Oxford Instuments Inca EDX system at the Electron Microscopy Facility of the Research Resource Center of the University of Illinois-Chicago. FT IR spectra were recorded on a Midac Systems spectrometer configured with a DTGS detector at a resolution of $4 \mathrm{~cm}^{-1}$.

Viability and proliferation tests. Viability and proliferation tests were performed by examining fibroblast proliferation patterns on various samples $(n=$ 6): porous $\mathrm{Si} / \mathrm{SiO}_{2}$, Alendronate-modified $\mathrm{Ca}_{3}\left(\mathrm{PO}_{4}\right)$ /porous $\mathrm{Si} / \mathrm{SiO}_{2}$, and $\mathrm{Ca}_{3}\left(\mathrm{PO}_{4}\right)$ films on porous $\mathrm{Si} / \mathrm{SiO}_{2}$. Cultures of fibroblast cells (passages 3-5) grown on T-75 flasks in Minimum Essential Media (MEM) supplemented with $10 \%$ Fetal Bovine Serum were maintained at $37^{\circ} \mathrm{C}$ in a $5 \% \mathrm{CO}_{2}$ incubator. Approximately $0.5-1 \times 10^{5}$ cells were seeded into each well of 6 well tissue culture dishes containing the $(n=6)$ samples. Cultures were re-fed every other day over an experimental duration of 7 days. The measurement of changes in number of attached cells was determined at days $1,3,5$, and 7 . After the designated incubation times, samples were transferred to empty culture plate wells and rinsed with PBS to remove loosely adherent cells. Samples were then incubated with $1 \mathrm{x}$ Trypsin-EDTA solution for approximately 3 minutes to detach the growing cells. Cell suspensions were then centrifuged at $850 \mathrm{rpm}$ for five minutes. Fibroblast cell pellets were resuspended in fresh MEM media and counted twice with the use of a hemacytometer. For viability count, cells were diluted in $0.1 \%$ Trypan blue and counted in a hemacytometer.

Image analysis. Fibroblast viability was monitored by labeling with intracellular fluorescent dye car- 

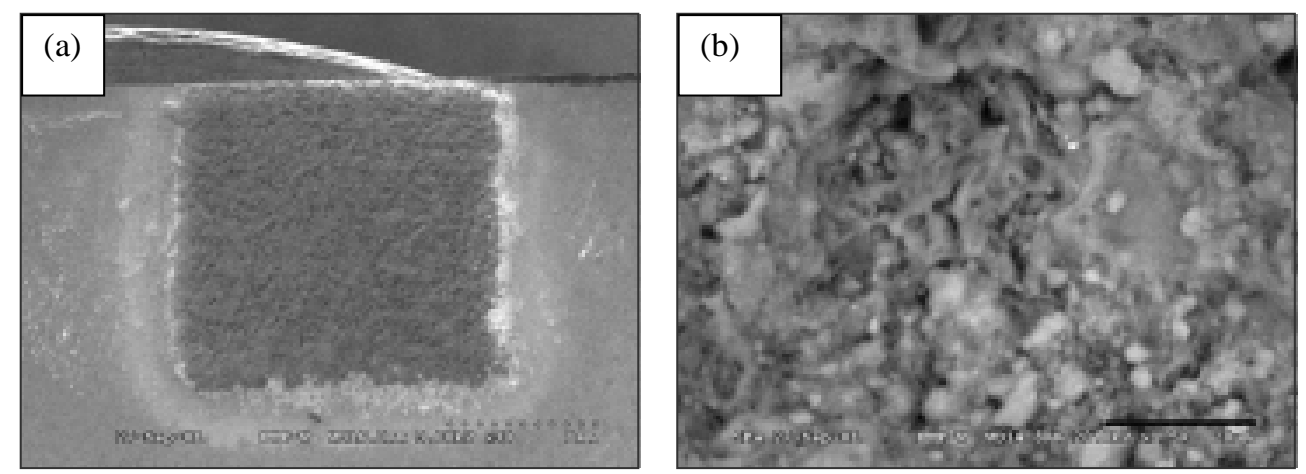

Fig. 1. Plan view SEM image of a porous calcium phosphate/silicon surface prepared by spark ablation in the presence of $\mathrm{Ca}_{0}\left(\mathrm{PO}_{4}\right)_{6}\left(\mathrm{OH}_{2} /\right.$ polycaprolactone (PCL). (a) low resolution image showing the overall pattern of the film. Scale bar shown is $1 \mathrm{~mm}$; (b) higher magnification image illustrating the rough porous morphology of the matrix. Scale bar is $20 \mu \mathrm{m}$.

boxyfluorescein diacetate succinimidyl ester (CMFDA) at a concentration of $5 \mu \mathrm{M}$. First, the CMFDA working solution was prepared in PBS. Cells were incubated with the prewarmed labeling solution at $37^{\circ} \mathrm{C}$ in a $5 \%$ $\mathrm{CO}_{2}$ containing incubator for 45 minutes. The labeling solution was then replaced by prewarmed fresh MEM medium supplemented with $10 \%$ FBS. Cells were allowed to incubate for 30 minutes and then viewed under the fluorescence microscope.

Cells were photomicrographed on day 7 at a magnification of 5x using an Olympus Oly-750 digital camera mounted on an Olympus BX60 image analysis microscope system.

\section{Results and discussion}

\subsection{Sample fabrication and characterization}

Utilizing the conditions noted above, porous wafer surfaces are readily produced by the spark ablation of a silicon wafer surface in the presence of calcium phosphate and poly-caprolactone. This is evidenced by an examination of the corresponding plan view scanning electron micrograph (SEM) (Fig. 1). From a perspective of composition, energy dispersive $\mathrm{x}$-ray analysis (XEDS) provides the most sensitive opportunity for elemental mapping in two dimensions. In Fig. 2, images associated with a given element (oxygen, silicon, calcium, and phosphorous) confirm the presence of calcium and phosphorous in the film. By an examination of the overlay EDX map (Fig. 3), the film structure is best described as a composite of calcium phosphate striations embedded in a porous silicon / silicon oxide matrix. Fourier transform infrared (FT IR) vibrational spectroscopy verifies that the characteristic phosphate stretching mode near $1030 \mathrm{~cm}^{-1}$ is present, along with a P-O deformation mode near $560 \mathrm{~cm}^{-1}$ and the $v(\mathrm{Si}-$ $\mathrm{O}-\mathrm{Si})$ and $v(\mathrm{Si}-\mathrm{Si})$ bands near 1100 and $610 \mathrm{~cm}^{-1}$, respectively. As noted previously, the relative intensities of these spectral features do not change upon prolonged exposure to solvents such as water (on the timescale of hours), indicating that the calcium phosphate films are rather strongly anchored to the underlying Si substrate [10].

SEM cross-sectional analysis for the above sample finds that the porous film possesses a thickness of approximately $25 \mu \mathrm{m}$ (Fig. 4), with some slight variation in this value across the substrate. Compared to our initial films of calcium phosphate on Si prepared by spark processing [10], we are able to produce relatively thicker (i.e. tens of microns) porous films by employing a mixed PCL/calcium phosphate slurry in conjunction with a three fold sparking sequence.

Derivatization of the calcium phosphate/porous $\mathrm{Si} / \mathrm{SiO}_{2}$ surface is readily achieved by exposure to an aqueous solution of alendronate, most commonly at a concentration of $5 \mathrm{mM}$. After immersion of a given calcium phosphate/porous $\mathrm{Si} / \mathrm{SiO}_{2}$ sample in this solution for an extended period of time at room temperature, the wafer is removed, washed thoroughly with water, and dried in a stream of dry nitrogen. As noted elsewhere, we have probed the presence of strongly-bound alendronate on the calcium phosphate surface by coupling the exposed primary amine groups at the surface with the fluorescent label fluorescein isothiocyanate) through simple immersion in an aqueous solution of the dye at room temperature. After thorough washing, the presence of the fluorescent label has been readily detected by fluorescence microscopy or quantitative spectroscopy. 


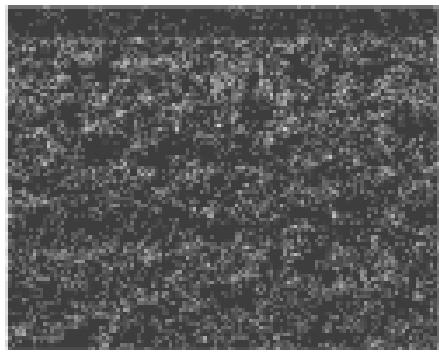

Oxygen Ka1_2

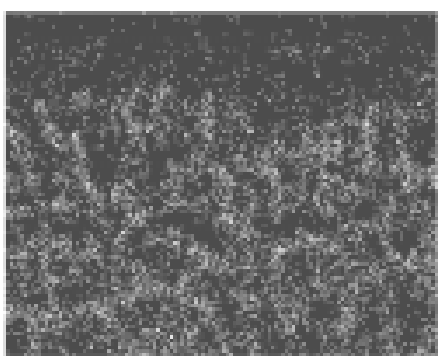

Phoephorus Kat

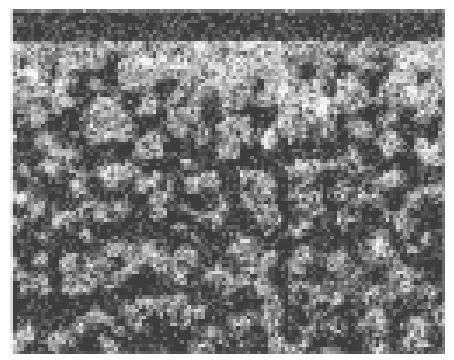

Siloon Ka1

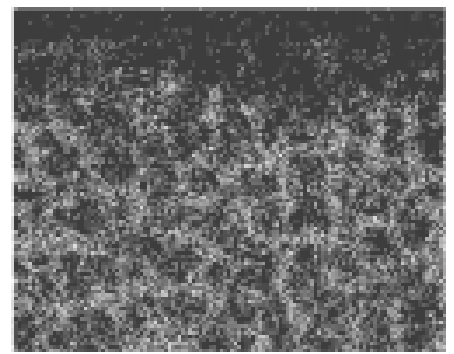

Calciun Kat

Fig. 2. Plan view EDAX element maps of the ablated calcium phosphate/porous silicon surface. (a) oxygen; (b) silicon; (c) phosphorus; (d) calcium.

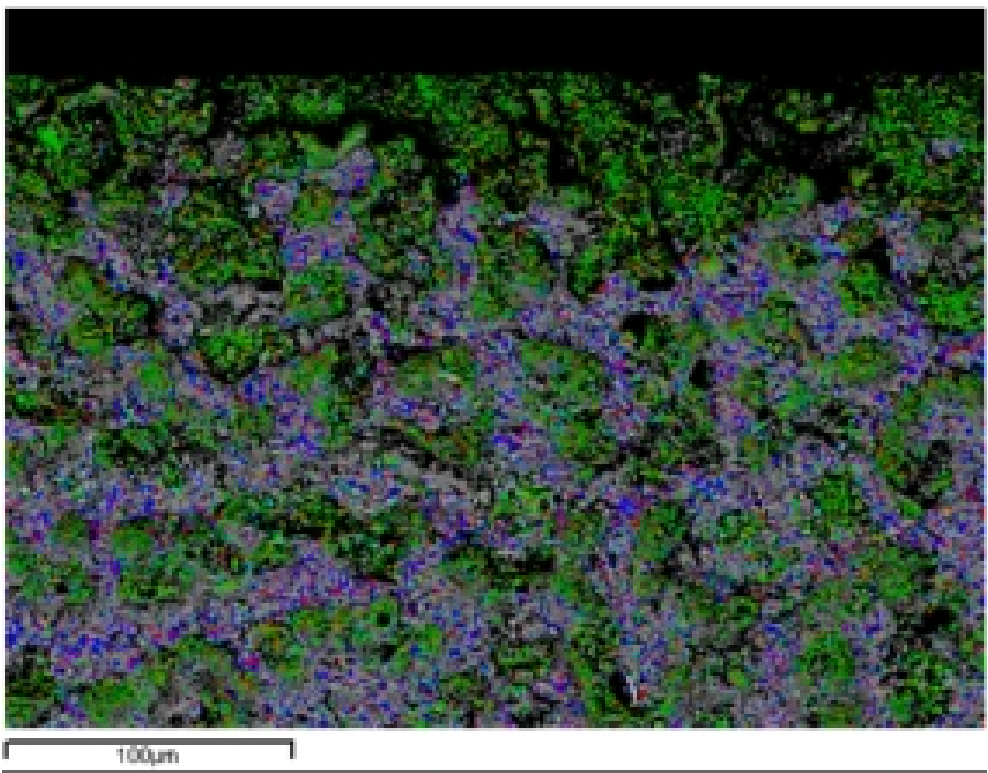

Fig. 3. Overlay plan view element map (EDAX) of the surface illustrated in Fig. 2. $\mathrm{Si}=$ green, $\mathrm{O}=\mathrm{red}, \mathrm{P}=$ blue, Ca $=$ gray. Scale bar is $100 \mu \mathrm{m}$.

\subsection{Cell viability and proliferation}

Figure 5 shows the change in number of adherent fibroblast cells on the various samples, determined at days $1,3,5$, and 7 , due to cell proliferation, detachment and/or death. Reported are average values of duplicate $(n=3)$ trials with standard deviations per dish.

The rates of change in adherent cell number proceeded to increase with time across all samples. Cells were found to attach and proliferate more readily on the $\mathrm{Ca}_{3}\left(\mathrm{PO}_{4}\right)_{2}$ containing films compared to the porous 


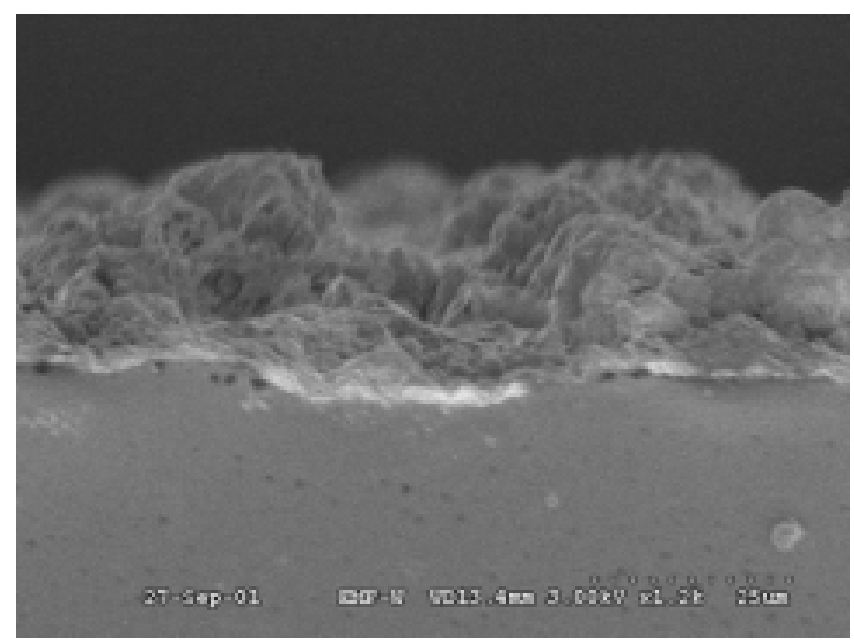

Fig. 4. Representative cross sectional SEM image of a porous calcium phosphate/silicon surface prepared by spark ablation in the presence of polycaprolactone. Scale bar is $25 \mu \mathrm{m}$.

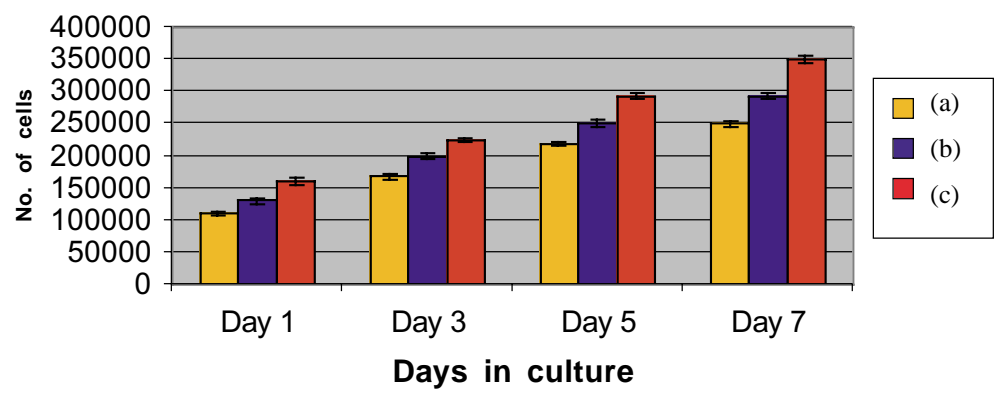

Fig. 5. Graph of the change in number of adherent fibroblast cells on the various samples, determined at days $1,3,5$, and $7 .(\mathrm{a})$ orange $=$ porous $\mathrm{Si} / \mathrm{SiO}_{2}$, (b) blue $=$ alendronate - modified $\mathrm{Ca}_{3}\left(\mathrm{PO}_{4}\right)_{2}$ on porous $\mathrm{Si} / \mathrm{SiO}_{2}$, (c) red $=\mathrm{Ca}_{3}\left(\mathrm{PO}_{4}\right)_{2}$ on porous $\mathrm{Si} / \mathrm{SiO}_{2}$.

$\mathrm{Si} / \mathrm{SiO}_{2}$ and alendronate modified- $\mathrm{Ca}_{3}\left(\mathrm{PO}_{4}\right)_{2}$ samples. Consistently throughout the 7 day experimental period, the $\mathrm{Ca}_{3}\left(\mathrm{PO}_{4}\right)_{2}$ surfaces exhibited the highest proliferation, followed by the alendronate-modified calcium phosphate materials and finally, the $\mathrm{Si} / \mathrm{SiO}_{2}$ control samples. The micrographs shown in Fig. 6 qualitatively support our numerical data, as the image representing the $\mathrm{Ca}_{3}\left(\mathrm{PO}_{4}\right)_{2}$ film on porous $\mathrm{Si} / \mathrm{SiO}_{2}$ shows a higher density of cells growing on the sample relative to the alendronate-modifed and porous $\mathrm{Si} / \mathrm{SiO}_{2}$ samples.

Given these results, it seems that these substrates are indeed biocompatible and can support cell growth over time. This may be important for designing in vivo platforms for therapeutic delivery and sensing. Previous work has shown several different biological effects of calcium-containing crystals on cells in vitro. Calcium phosphate crystals have been shown to exert biological effects on cultured cells in a manner similar to growth factors like platelet-derived growth factor, epidermal growth factor, and serum [15]. It has also been demonstrated that BCP crystals stimulate fibroblast, synoviocyte, and chondrocyte mitogenesis in vitro [16], and induce the synthesis and secretion of metalloproteinases (MMPs) 1, 3, 8, and 13 [17].

Cell mediated resorption and enhanced deposition have been observed on calcium phosphate thin films formed by high temperature processing of an HA colloid on quartz substrata [18]. This is consistent with our observations that greater cell binding occurs on $\mathrm{Ca}_{3}\left(\mathrm{PO}_{4}\right)_{2}$, compared to the porous $\mathrm{Si} / \mathrm{SiO}_{2}$ and alendronate-modified calcium phosphate samples.

Our in vitro results also correlate to in vivo studies looking at the effect of calcium phosphates on the formation fibrous tissue capsules. For both subcutaneous and intraperitoneal implantation sites, the fibrous tissues surrounding the tri-calcium phosphate bioceramics demonstrated greater capsular thickness, more vascularity, and more macrophages, fibroblasts, and collagen than those surrounding the aluminum-calcium 


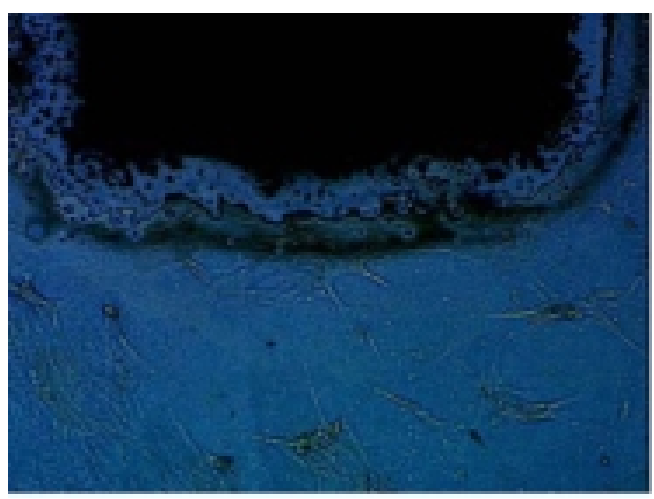

(a)

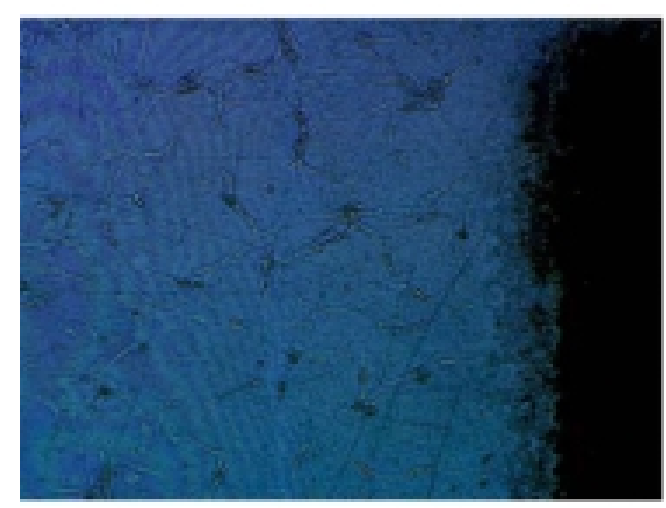

(b)

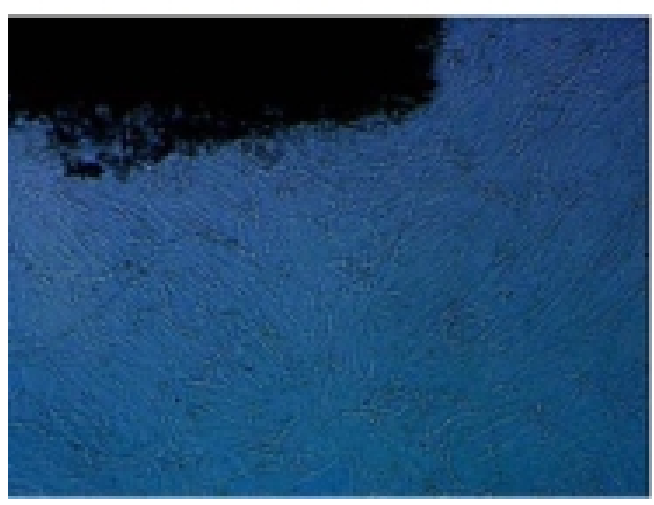

(c)

Fig. 6. Micrographs of fibroblasts at day 7 grown on the following surfaces a) porous $\mathrm{Si} / \mathrm{SiO}_{2}$, (b) Alendronate-modified $\mathrm{Ca}_{3}\left(\mathrm{PO}_{4}\right)_{2}$ on porous $\mathrm{Si} / \mathrm{SiO}_{2}$, (c) $\mathrm{Ca}_{3}\left(\mathrm{PO}_{4}\right)_{2}$ on porous $\mathrm{Si} / \mathrm{SiO}_{2}$.

phosphate ceramic [19]. Thus, hybrid calcium phosphate platforms on semiconducting surfaces may be more suitable for in vivo biosensing platforms than conventional glass or silicon substrates.

\section{Summary}

The above experiments clearly confirm our expectation that the surface chemistry of the calcified sili- con surface plays a role in mediating cellular recognition events, demonstrated explicitly in this case with fibroblasts. The extent of 'tunability' of this activity, and associated binding events relevant to sensing, are experiments currently under design in our laboratories.

\section{Acknowledgements}

The authors gratefully acknowledge the National Institutes of Health (TAD), the Texas Advanced Technology Program (JLC) and the Robert A. Welch Foundation (JLC, JLM) for financial support.

\section{References}

[1] K.D. Wise and K. Najati, in: VLSI in Medicine, N.G. Einspruch and R.D. Gold ed., (Academic Press, New York, 1989) Chap. 10.

[2] T.A. Desai, D.J. Hansford, L. Kulinsky, A.H. Nashat, G. Rasi, J. Tu,. Y. Wang, M. Zhang and M. Ferrari, Nanopore Technology for Biomedical Applications, Biomed. Microdevices 2 (1999), 11-40.

[3] S.S. Stensas and L.J. Stensas, Acta Neuropathologica 41 (1978), 145.

[4] D.J. Edell, V.V. Toi and V.M. McNeil, Factors Influencing the Biocompatibility of Insertable Silicon Microshafts in Cerebral Cortex, IEEE Trans. Biomed. Engr. 39 (1992), 635-643.

[5] L.T. Canham, Bioactive Silicon Structure Fabrication Through Nanoetching Techniques, Adv. Mater. 7 (1995), 1033-1037.

[6] L.T. Canham, J.P. Newey, C.L. Reeves, M.R. Houlton, A. Loni, A.J. Simons and T.I. Cox, The Effects of DC Electric Currents on the In-Vitro Calcification of Bioactive Silicon Wafers, Adv. Mater. 8 (1996), 847-849.

[7] L.T. Canham, J.P. Newey, C.L. Reeves, D.O. King, P.J. Branfield, J.G. Crabb and M.C.L. Ward, Bioactive Polycrystalline Silicon, Adv. Mater. 8 (1996), 850-852.

[8] X. Li, J.L. Coffer, Y. Chen, R.F. Pinizzotto, J.P. Newey and L.T. Canham, Transition Metal Complex-Doped Hydroxyapatite Layers on Porous Silicon, J. Am. Chem. Soc. 120 (1998), 11706-11709.

[9] J. Ji, X. Li, J.L. Coffer and L.T. Canham, Use of Microcontact Printing Methods to Direct Pattern Formation of Calcified Nanoporous Silicon, Adv. Mater. 14 (2002), 41-43.

[10] R.W. Weis, Y. Chen and J.L. Coffer, The Use of Spark Ablation to Produce Calcium Phosphate Films on Silicon, Electrochem. Solid State Lett., 5 (2002), C22-24.

[11] X. Li, J. St. John, J.L. Coffer, Y. Chen, R.F. Pinizzotto, J.P. Newey and L.T. Canham, Porosified Silicon Wafer Structures Impregnated With Platinum Anti-Tumor Compounds: Fabrication, Characterization, and Diffusion Studies, Biomed. $\mathrm{Mi}$ crodevices 2 (2000), 265-272.

[12] X. Li and J.L. Coffer, DNA Binding to Fluorescent Ruthenium Species Released from Calcium Phosphate/Nanoporous Silicon Structures, J. Nanosci. Nanotech., special issue on Nanodevices, in press 2002.

[13] G.A. Rodan and T.J. Martin, Therapeutic Approaches to Bone Diseases, Science 289 (2000), 1508-1514. 
[14] J.B. Aimone, J.-L. Montchamp and J.L. Coffer, Bisphosphonates as Ligands for the Selective Modification of Calcified Porous Silicon, submitted for publication.

[15] P.M. Reuben, M.A. Brogley, Y. Sun and H.S. Cheung, Molecular Mechanism of the Induction of Metalloproteinases 1 and 3 in Human Fibroblasts by Basic Calcium Phosphate Crystals, Biol. Chem., Vol. 277(Issue 17) (April 26, 2002), 1519015198 ,

[16] H.S. Cheung, J.J. Van Wyk, W.E. Russell and D.J. McCarty, J. Cell. Physiol. 128 (1986), 143-148.

[17] P.M. Reuben, L. Wenger, M. Cruz and H.S. Cheung, Induction of matrix metalloproteinase- 8 in human fibroblasts by basic calcium phosphate and calcium pyrophosphate dihydrate crystals: effect of phosphocitrate, Conn. Tissue Res. 42 (2001), $1-12$.

[18] S. Langstaff, M. Sayer T.J.N. Smith and S.M. Pugh, Resorbable bioceramics based on stabilized calcium phosphates. Part II: evaluation of biological response, Biomaterials 22 (2001), 135-150.

[19] K.R. Butler, H.A. Benghuzzi and A. Puckett, Morphometric evaluation of tissue-implant reaction associated with ALCAP and TCP bioceramics in vivo, J Invest Surg. 14 (2001), 139152. 


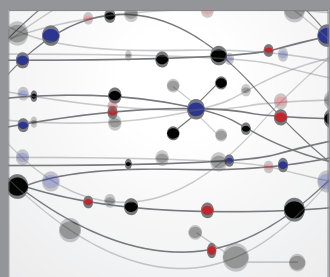

The Scientific World Journal
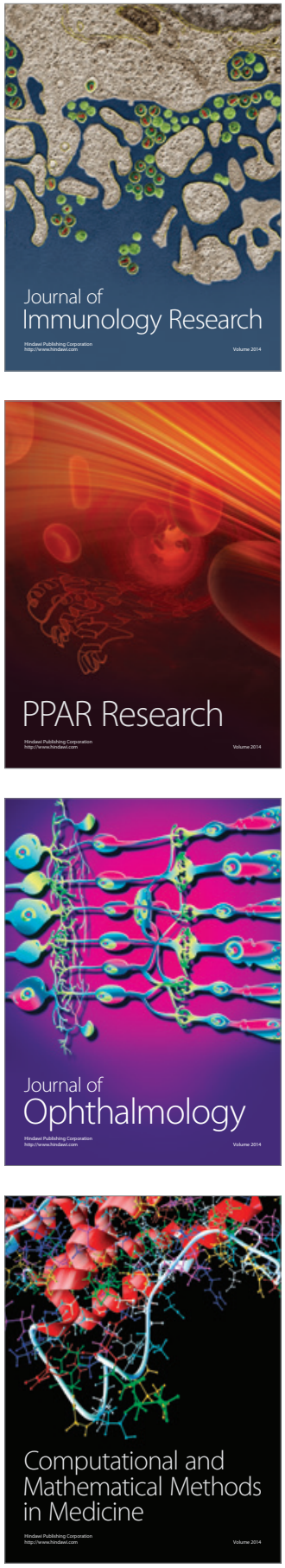

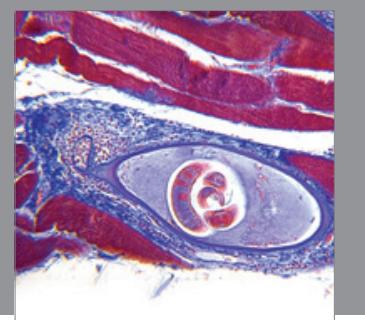

Gastroenterology

Research and Practice
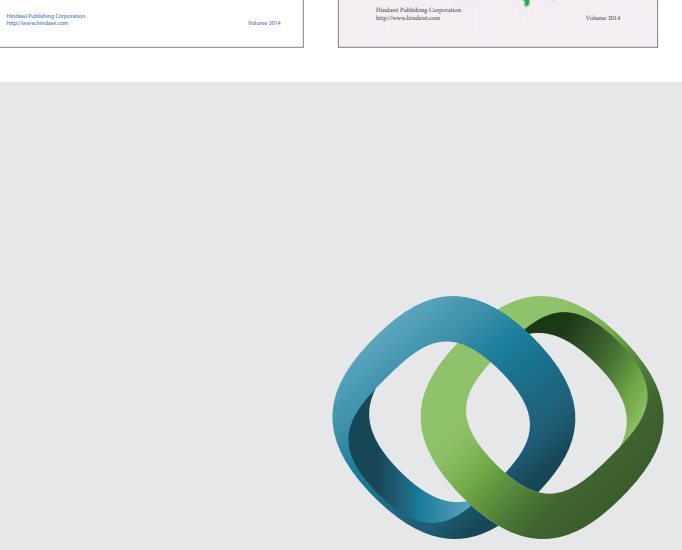

\section{Hindawi}

Submit your manuscripts at

http://www.hindawi.com
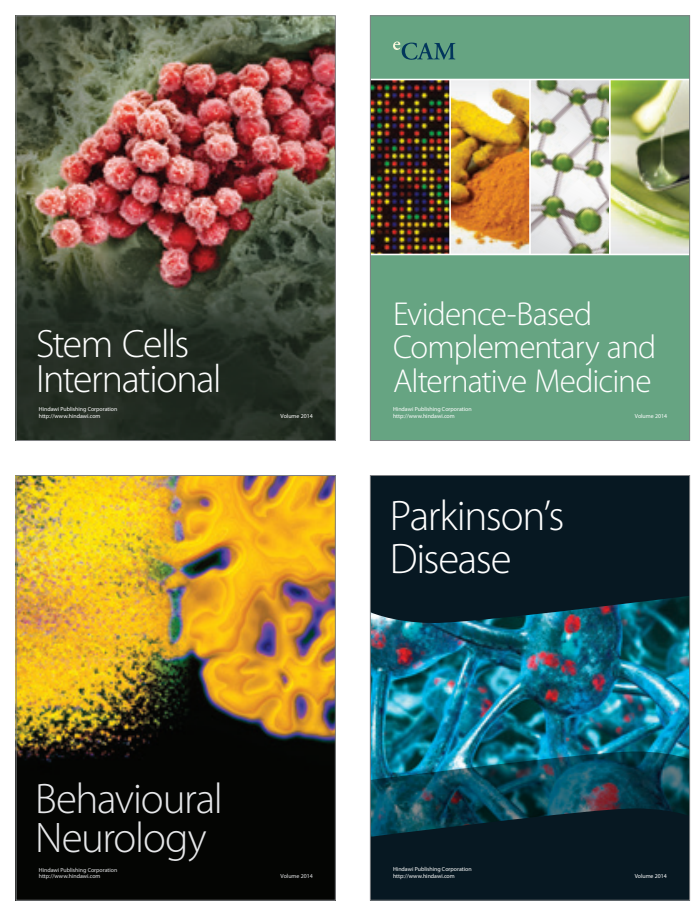

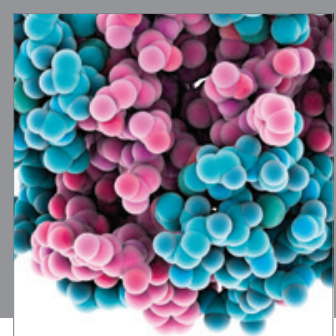

Journal of
Diabetes Research

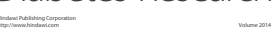

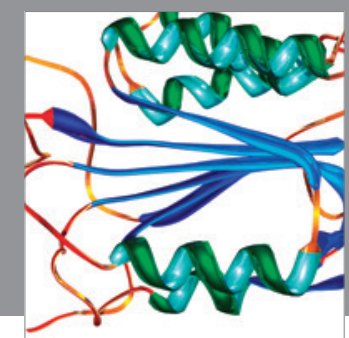

Disease Markers
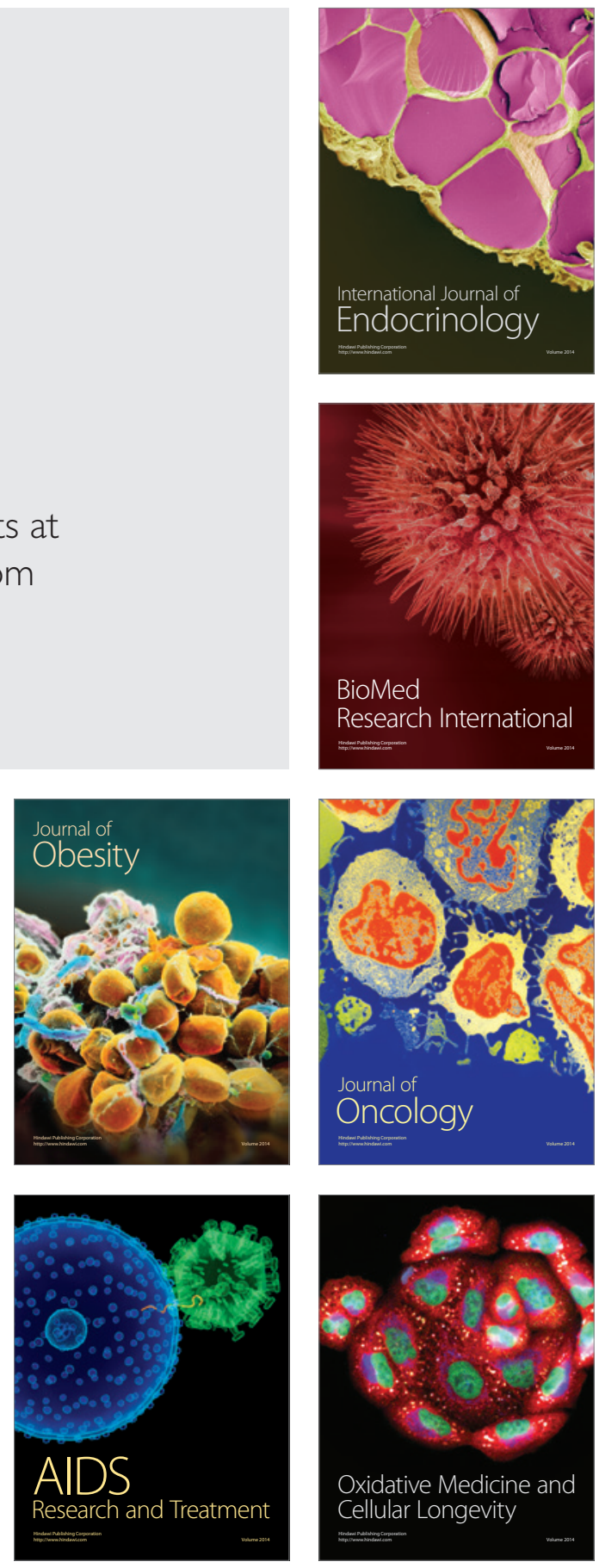